\title{
Breast Cancer Surgery at a Cancer Center in Janakpurdham: An Initial Experience
}

\author{
Pamesh Jha, Anshu K Thakur, Sanjay Gupta, Richa Mishra, Yogendra P Singh \\ Binaytara Foundation Cancer Center, Kadam Chowk, Kapileshwore Marg, Janakpurdham, Nepal
}

\section{Corresponding author:}

Pamesh Jha, MBBS, MS

Binaytara Foundation Cancer Center, Kadam Chowk, Kapileshwore Marg, Janakpurdham, Nepal Email: pamesh.jha@gmail.com

\begin{abstract}
\section{Introduction}

Breast cancer is the second commonest cancer in Nepalese women. In most of the low income countries including Nepal, breast cancer is commonly diagnosed at late stage. The Binaytara Foundation Cancer Center (BTFCC), a 25 bed cancer hospital was established in Province 2, the most densely populated province, of Nepal in December 2018. We describe our experience of breast cancer surgery at the cancer hospital.
\end{abstract}

\section{Methods}

Surgical service was started from April 2019 after establishing an equipped operating room and postoperative and ICU wards. Total 51 surgeries were performed for both benign and malignant diseases by the end of 2019. The commonest surgery was breast surgery in 18 patients. Retrospective analysis of all six patients who were operated for breast cancer at the cancer center was done.

\section{Results}

Six female patients of this province were operated for breast cancer during this period. Age ranged from 40 to 56 years. Four patients were presented with locally advanced disease. Two patients received neoadjuvant chemotherapy and two were subjected for upfront surgery. Modified radical mastectomy was done in four patients. For one patient with suspected hereditary localized breast cancer and one with Paget's disease of the breast with non invasive ductal carcinoma, simple mastectomy was performed. Postoperative period was uneventful except one case with seroma formation. Other than one Paget's disease of the breast, all were triple nipple breast cancer.

\section{Conclusion}

Breast cancer surgery is one of the important modality of treatment even for locally advanced disease in resource limited settings.

Keywords: Breast cancer, outcome, mastectomy 